\title{
URBAN GROWTH MODELING USING ANFIS ALGORITHM: A CASE STUDY FOR SANANDAJ CITY, IRAN
}

\author{
Mohammady, S. ${ }^{1}$, M. R. Delavar ${ }^{2}$ and B. C. Pijanowski ${ }^{3}$
}

${ }^{1}$ GIS MSc. student, Dept. of Surveying and Geomatics Eng., College of Eng.,

University of Tehran, Tehran, Iran

Sassanmohammady@ut.ac.ir

${ }^{2}$ Center of Excellence in Geomatic Eng. in Disaster Management, Dept. of Surveying and Geomatic Eng., College of Eng., University of Tehran, Tehran, Iran

mdelavar@ut.ac.ir

${ }^{3}$ Dept. of Forestry and Natural Resources, College of Agriculture, Purdue University,

West Lafayette, IN 47907, USA

bpijanow@purdue.edu

KEY WORDS: Urban Growth, Modelling, ANFIS, GIS

\begin{abstract}
:
Global urban population has increased from $22.9 \%$ in 1985 to $47 \%$ in 2010 . In spite of the tendency for urbanization worldwide, only about $2 \%$ of Earth's land surface is covered by cities. Urban population in Iran is increasing due to social and economic development. The proportion of the population living in Iran urban areas has consistently increased from about $31 \%$ in 1956 to $68.4 \%$ in 2006 . Migration of the rural population to cities and population growth in cities have caused many problems, such as irregular growth of cities, improper placement of infrastructure and urban services. Air and environmental pollution, resource degradation and insufficient infrastructure, are the results of poor urban planning that have negative impact on the environment or livelihoods of people living in cities. These issues are a consequence of improper land use planning.
\end{abstract}

Models have been employed to assist in our understanding of relations between land use and its subsequent effects. Different models for urban growth modeling have been developed. Methods from computational intelligence have made great contributions in all specific application domains and hybrid algorithms research as a part of them has become a big trend in computational intelligence. Artificial Neural Network (ANN) has the capability to deal with imprecise data by training, while fuzzy logic can deal with the uncertainty of human cognition. ANN learns from scratch by adjusting the interconnections between layers and Fuzzy Inference Systems (FIS) is a popular computing framework based on the concept of fuzzy set theory, fuzzy logic, and fuzzy reasoning. Fuzzy logic has many advantages such as flexibility and at the other sides, one of the biggest problems in fuzzy logic application is the location and shape and of membership function for each fuzzy variable which is generally being solved by trial and error method. In contrast, numerical computation and learning are the advantages of neural network, however, it is not easy to obtain the optimal structure. Since, in this type of fuzzy logic, neural network has been used, therefore, by using a learning algorithm the parameters have been changed until reach the optimal solution. Adaptive Neuro Fuzzy Inference System (ANFIS) computing due to ability to understand nonlinear structures is a popular framework for solving complex problems. Fusion of ANN and FIS has attracted the growing interest of researchers in various scientific and engineering areas due to the growing need of adaptive intelligent systems to solve the real world problems. 
In this research, an ANFIS method has been developed for modeling land use change and interpreting the relationship between the drivers of urbanization. Our study area is the city of Sanandaj located in the west of Iran. Landsat images acquired in 2000 and 2006 have been used for model development and calibration. The parameters used in this study include distance to major roads, distance to residential regions, elevation, number of urban pixels in a 3 by 3 neighborhood and distance to green space. Percent Correct Match (PCM) and Figure of Merit were used to assess model goodness of fit were $93.77 \%$ and $64.30 \%$, respectively.

\section{Introduction}

Urban population in the world has been increased from $22.9 \%$ in 1985 to $47 \%$ in 2010. Tendency to urbanization and rapid population growth has resulted that above $2 \%$ of Earth's land surface covered by urban areas [1]. One of the results of this urban population growth is large-scale urban expansion [2, 3]. Rapid growth of urban areas has led to complex problems, including reduced open space, traffic problems, environmental pollution, the deterioration of old and unplanned or poorly planned land development [4]. One of the major problems in intelligent management of cities is the lack of proper and scientific development and as a result destruction of agricultural land, urban development in high slope and elevations, environmental deteriorate and natural hazards, increased infrastructure and utilities costs and the lack of optimum use of land have been encountered. Thus, monitoring of land use changes is needed to understand and predict the dynamic process of land use patterns at different times. A vital component of the research on land use/cover change is the analysis of rates and patterns of land use change which is a powerful tool for urban planners, city and resource managers $[5,6,7,8]$. Land use change models as a tool are used to show where, when and how changes could arise in the future in order to adapt current public policy $[9,10]$. In the past decades, different models have been developed to exhibit and quantify land use changes $[11,12$, $13,14]$, mainly in land-use change (LUC) models. In this paper we implement ANFIS algorithm as a new approach in environmental modeling such as urban growth modeling. Percent Correct Match (PCM) and Figure of Merit (FoM) have been used to evaluate urban growth modeling accuracy.
In recent decades, remote sensing data and Geospatial Information System (GIS) have been widely applied for identification and analyses of land use change in metropolitan area $[15,16,17,18,19,20,21]$. Remote sensing imageries data have been used in urban growth modeling, urban morphology and land uses [22, 23, 24], quantifying land use dynamics and urban growth [25, 26, 27, 28]. Geospatial Information Systems (GIS) are widely used to represent, analyze, and display various spatial data such as remote sensing, topography, soil type, rainfall and vegetation [29]. In this study, two Landsat TM and $\mathrm{ETM}^{+}$ satellite imageries with $28.5 \mathrm{~m}$ and $30 \mathrm{~m}$ spatial resolution acquired in 2000 and 2006 were used. These images were obtained from the United States Geological Survey (USGS) portal. Data were projected to a World Geodetic System (WGS) 1984, Universal Transverse Mercator (UTM) Zone 38N coordinate system. Registration errors were about 0.50 pixels. The 2000 and 2006 Landsat imageries were classified according to Anderson level 1 with ENVI software. Maximum Likelihood classification has been used to classify the imageries. Overall accuracy and kappa coefficient of these imageries were $94.71 \%$ and $92.68 \%$ for $2006,92.57 \%$ and $89.17 \%$ for 2000 , respectively. Fig. 1 shows the Landsat imageries. We have used $10 \%$ of 2000 and 2006 imageries data for calibrating models and rest of the data have used to simulate the urban pattern at 2006. Datasets employed include five parameters include distance to roads, distance to green spaces, distance to residential areas, elevation and number of urban pixels in a $3 * 3$ neighborhood. Following [30], each value in an entire predictor variable map (e.g., distance to green space) was normalized by dividing each value by the maximum value contained in the predictor variable map (Fig. 2). 


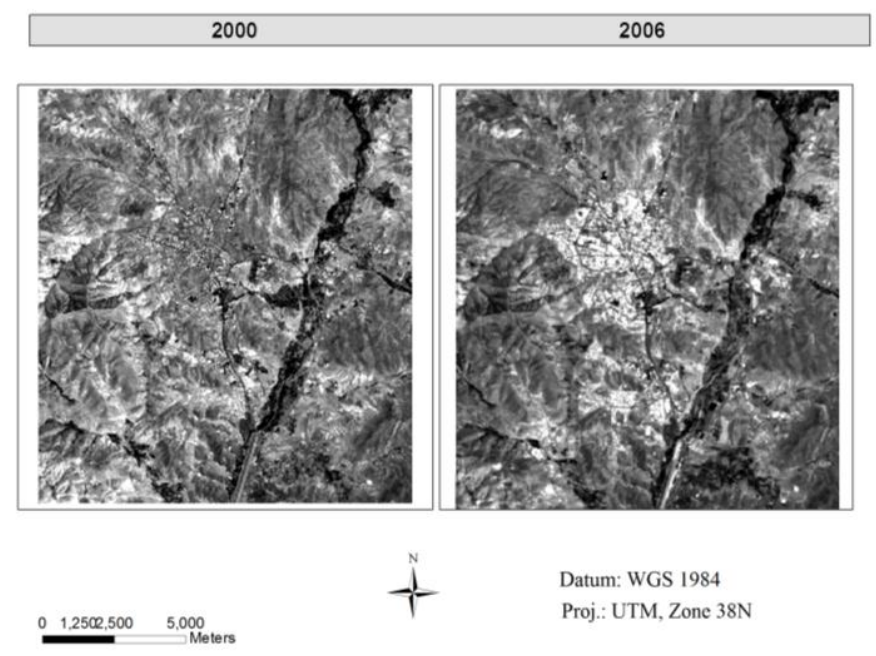

Figure 1 Sanandaj satellite imageries

\section{Methods}

ANFIS is a multi-layer adaptive network-based fuzzy inference system proposed by [31]. Fuzzy inference system is a method which the most important feature is its ability to apply human knowledge and expertise causing this system to be very close to human perception. In addition, it is a powerful tool for modeling uncertainties associated with human cognition, thinking and perception. This flexibility is one of its advantages. The most important problem in fuzzy inference system is finding proper membership function for each fuzzy variable. On the other side, ANN has the ability to learn pattern and relationship between data from educational data. Combining these two methods is the way to learn human knowledge. Furthermore, it cover a number of shortcomings, such as the problem of finding the correct position and shapes for membership functions in fuzzy inference system and lack of flexibility in neural network. In other words, learning, use of human knowledge and flexibility are ANFIS advantages which make this method to be very suitable to solve some of complex systems. In the other words, during the learning process, membership functions changes toward their optimal values.

In this study we implemented a grid partition ANFIS which Gaussian bell function is the membership function. Table 1 describes the membership functions $(\mathrm{mf})$ in this study. MSE were obtained 0.2085 in 100 epochs.

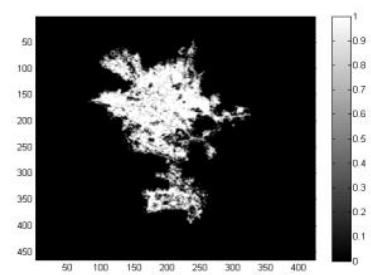

number of urban pixels in a

$3 * 3$ neighborhood

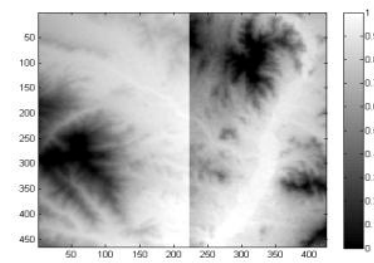

Elevation

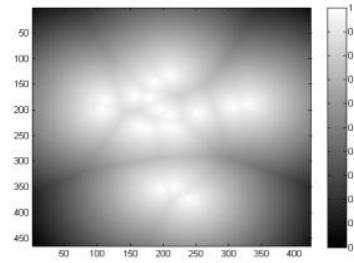

Distance to Green spaces

Figure 2 The normalized input dataset

\begin{tabular}{|c|l|c|}
\hline Inputs & $\mathrm{mf}$ & Number of $\mathrm{mf}$ \\
\hline Dis2 green space & Gaussian bell & 3 \\
\hline Dis2 residential area & Gaussian bell & 3 \\
\hline Dis2 main road & Gaussian bell & 3 \\
\hline slope & Gaussian bell & 2 \\
\hline $\begin{array}{c}\text { number of urban pixels } \\
\text { in a } 3 * 3 \text { neighborhood }\end{array}$ & Gaussian bell & 2 \\
\hline
\end{tabular}

Table 1. Membership functions for each input 


\section{Result and Discussion}

The study area in this research is Sanandaj city, in the west of Iran. In the past few decades, Sanandaj has shown remarkable urban growth. One of the reasons for the rapid population growth in this in this city is migration from neighboring cities and even from neighboring provinces to the city because of the economic and social potential of this city. We evaluated our accuracy using FoM and PCM parameters. According to the definition of these parameters, they are good parameters to show us modeling accuracy.

\section{Figure of Merit}

Figure of Merit (Equation 1) is a method to evaluate resemblance between actual and simulated map suggested first time by [32]. If simulated map have a high goodness of fit to actual map, Figure of Merit will be high and vice versa.
Figure of Merit $=\frac{b}{a+b+c+d}$

where;

$a=$ error due to observed change predicted as persistence

$b=$ correct due to observed change predicted as change

$c=$ error due to observed change predicted as wrong gaining category

$d=$ error due to observed persistence predicted as change

\section{PCM}

Percent Correct Match (PCM) is a way to evaluate models of urban development. This method compares only the parameters of the original diameter of the $\mathrm{A}$ and $\mathrm{D}$ in the confusion matrix using Equation 2 (Table 2) [33].

$$
P C M=\frac{A+D}{A+B+C+D}
$$

\begin{tabular}{|cc|c|c|}
\hline \multirow{2}{*}{ Model } & \multicolumn{3}{c|}{ Reality } \\
\cline { 2 - 4 } & \multicolumn{3}{c|}{ Non Change } \\
\cline { 2 - 4 } $\begin{array}{c}\text { Change } \\
\text { Change } \\
\text { Non Change } \\
\text { Total }\end{array}$ & $\mathrm{A}$ & $\mathrm{B}$ & A+B \\
\cline { 2 - 4 } & $\mathrm{C}$ & $\mathrm{D}$ & $\mathrm{C}+\mathrm{D}$ \\
\hline
\end{tabular}

Table 2. Confusion matrix

After the model calibration using historical observed data (10\%) of the year 2000 and 2006, the model simulated (the rest of the data) the urban pattern (year 2006) based on current urban growth trends (Fig. 3). 

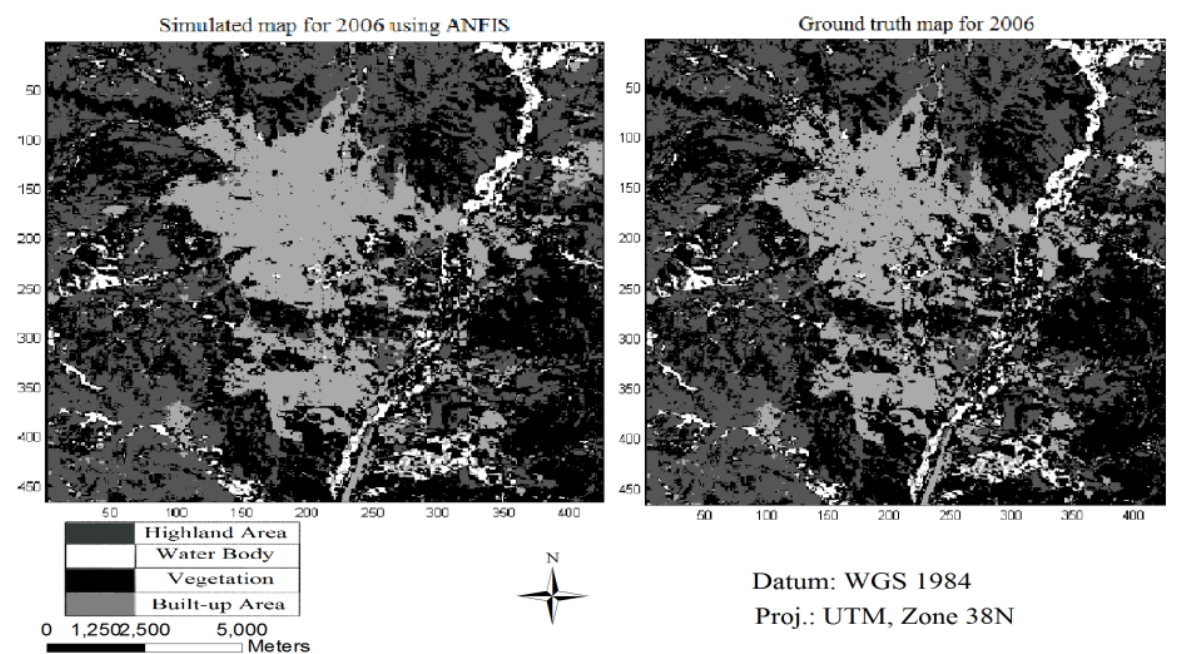

Figure 3 Simulated map compare with ground truth map for 2006

\section{Conclusion}

This study employed ANFIS algorithm in urban growth modeling for Sanandaj city between 2000 and 2006 (Fig 5). PCM and FoM are obtained $93.77 \%$ and $64.30 \%$, respectively.

The rum time program in this algorithm directly depend on the number of membership functions. On the other hand, greater number of membership function means better accuracy. Thus, selection of proper number of membership function is a big challenge in using ANFIS

The implemented algorithm, can be considered as a powerful method in environmental modeling such as urban expansion pattern. This method employ ANN and fuzzy inference system abilities to understand relation between inputs and output and perceive complex pattern such as urban patterns.

of Sciences of the United States of America, 101(39), 13976-13981.

[8] Turner II, B.L., Lambin, E.F., and Reenberg, A., 2007. The emergence of land change science for global environmental change and sustainability. The National Academy of Sciences of the United States of America 104, 20666-20671.

[9] Conway, T. M., and Lathrop, R. G. (2005), Modeling the ecological consequences of land-use policies in an urbanizing region. Environmental Management, 35(3), 278-291

[10] Lambin, E., 1997, Modeling and monitoring land-cover change processes in tropical regions. Progr. Phys. Geogr. 21, 375-393.

[11] Irwin, E. G., and Geoghegan, J. (2001). Theory, data, methods: developing spatially explicit economic models of land use change. Agriculture, Ecosystems and Environment, 85, 7-23.

[12] Parker, D. C., Manson, S. M., Janssen, M. A., Hoffmann, M. J., and Deadman, P. (2003). Multi-agent systems for the simulation of land-use and land-cover change: a review. Annals of the Association of American Geographers, 93(2), 314-337.

[13] Veldkamp, A., and Lambin, E. F. (2001), Predicting land-use change. Agriculture, Ecosystems and Environment, 85, 1-6.
[7] Rindfuss, R. R., Walsh, S. J., Turner, B. L., II., Fox, J., and Mishra, V., 2004, Developing a science of land change:

Challenges and methodological issues. The National Academy
[6] Lambin, E.F., Geist, H. (Eds.), 2006. Land-use and cover Change: Local Processes, Global Impacts. The Synthesis Report of the Land Use and Cover (LUCC) Project of IHDP and IGBP. Springer, Berlin. 
[14] Verburg, P. H., Ritsema van Eck, J., de Nijs, T., Schot, P., and Dijst, M. (2004), Determinants of land-use change patterns in the Netherlands, Environment and Planning B, 31, 125-150.

[15] Dewan, A.M., and Yamaguchi, Y, 2008, Using remote sensing and GIS to detect and monitor land use and land cover change in Dhaka Metropolitan of Bangladesh during 1960-2005. Environ. Monit. Assess. Doi:10.1007/s10661-008-0226-5.

[16] Tayyebi, A., Pijanowski, C., and Pekin, B., 2011,” Two rulebased urban growth boundary models applied to the Tehran Metropolitan Area, Iran”, Applied Geography 31, 908-918

[17] Xie, Y.C.; Fang, C.L.; Lin, C.S., Gong, H.M., and Qiao, B., 2007, Spatio-temporal patterns of land use changes and urban development in globalization China: a study of Beijing. Sensors, 7, 2881-2907.

[18] Aguilera, F., Valenzuela, L, M., and Botequilha-Leitão, A., 2011, "Landscape metrics in the analysis of urban land use patterns: A case study in a Spanish metropolitan area". Landscape and Urban Planning 99, 226-238

[19] Hana, J., Hayashia, Y., Caob, X., and Imuraa, H., 2009, "Application of an integrated system dynamics and cellular automata model for urban growth assessment: A case study of Shanghai, China". Landscape and Urban Planning 91, 133-141

[20] Rojas, C., Pino, J., Basnou, C., and Vivanco, M., 2013, "Assessing land-use and -cover changes in relation to geographic factors and urban planning in the metropolitan area of Concepción (Chile). Implications for biodiversity conservation". Applied Geography 39, 93-103

[21] Ying Long, Y., Han, H., Lai, S., and Mao, Q., 2013, "Urban growth boundaries of the Beijing Metropolitan Area: Comparison of simulation and artwork". Cities 31, 337-348

[22] Long, H.L.; Tang, G.P.; Li, X.B., and Heilig, G.K., 2007, Socio-economic driving forces of land-use change in Kunshan, the Yangtze River Delta Economic Area of China. J. Environ. Manage. , 83, 351-364.

[23] Long, H.L., Wu, X.Q., Wang, W.J., and Dong G.H., 2008, Analysis of urban-rural land-use change during 1995-2006 and its policy dimensional driving forces in Chongqing, China. Sensors $8,681-699$.
[24] Jat, M.K., Garg, P.K., and Khare, D., 2008, Monitoring and modeling of urban sprawl using remote sensing and GIS techniques. Int. J. Appl. Earth Obs. Geoinf. 10, 26-43.

[25] Thapa, R. B., and Murayama, Y, 2009, "Examining spatiotemporal urbanization patterns in Kathmandu Valley, Nepal: Remote Sensing and Spatial Metrics Approaches". Remote Sens. 1, 534-556; doi:10.3390/rs1030534

[26] Fung, T., 1990, An assessment of TM imagery for landcover change detection. IEEE Trans. Geosci. Rem. Sen. 28, 681684

[27] Li, X., A, and G, Yeh., 2004, Analyzing spatial restructuring of land use patterns in a fast growing region using remote sensing and GIS, Landscape and Urban Planning 69, 335-354

[28] Harries, P. M., and Ventura, S. J., The integration of geographic data with remotely sensed imagery to improve classification in an urban area. Photogrammertric Engineering and Remote Sensing1995, 61, 381-385.

[29] Li, X., and Yeh, A.G.O., Analyzing spatial restructuring of land use patterns in a fast growing region using remote sensing and GIS. Landscape Urban Plan. 2004, 69, 335-354.

[30] Pijanowski, B.C., Brown, D.G., Shellito, B.A., and Manik, G.A., 2002, Using neural networks and GIS to forecast land use changes: a land transformation model. Comput. Environ. Urban 26 (6), 553-575

[31] Jang, J.S.R., 1993, ANFIS: adaptive-network-based fuzzy inference system: IEEE Tran. on Sys., Man and Cybernetics, 23(3): 665-685

[32] Pontius Jr., R.G., Boersma, W., Castella, J.C., Clarke, K., de Nijs, T., Dietzel, C., Zengqiang, D., Fotsing, E., Goldstein, N., Kok, K., Koomen, E., Lippitt, C.D., McConnell, W., Pijanowski, B., Pithadia, S., Sood, A.M., Sweeney, S., Trung, T.N., Veldkamp, and A.T., Verburg, P.H., 2008, Comparing the input, output, and validation maps for several models of land change. Annals of Regional Science, 42: $11-47$.

[33] Pontius Jr., R. G., and Schneider, L. C., 2001, Land-cover change model validation by an ROC method for the Ipswich watershed, Massachusetts, USA. Agriculture, Ecosystems \& Environment, $\quad$ 85(1-3), $239-248$ 